\title{
Single nucleotide polymorphisms of the haptoglobin gene in non-small cell lung cancer treated with personalized peptide vaccination
}

\author{
KAYOKO WAKI $^{1}$, TEPPEI YAMADA ${ }^{2}$, KOICHI YOSHIYAMA $^{3}$, YASUHIRO TERAZAKI ${ }^{3}$, \\ SHINJIRO SAKAMOTO ${ }^{2}$, SHUNICHI SUGAWARA ${ }^{4}$, SHINZO TAKAMORI $^{3}$, KYOGO ITOH $^{2}$ and AKIRA YAMADA ${ }^{1}$ \\ ${ }^{1}$ Cancer Vaccine Development Division, Kurume University Research Center for Innovative Cancer Therapy; \\ ${ }^{2}$ Kurume University Cancer Vaccine Center; ${ }^{3}$ Department of Surgery, Kurume University School of Medicine, Kurume, \\ Fukuoka 830-0011; ${ }^{4}$ Department of Pulmonary Medicine, Sendai Kousei Hospital, Sendai, Miyagi 980-0873, Japan
}

Received August 10, 2015; Accepted October 6, 2016

DOI: $10.3892 / \mathrm{ol} .2016 .5467$

\begin{abstract}
The present study analyzed polymorphisms of the 5 ' flanking region (from nt -840 to +151 ) of the haptoglobin gene in 120 patients with advanced non-small cell lung cancer (NSCLC) receiving personalized peptide vaccinations. In the region, six single nucleotide polymorphisms (SNPs) were confirmed, of which two, rs5472 and rs9927981, were completely linked to each other. The minor allele frequencies of rs5472/rs9927981 and rs4788458 were higher than those of the other three SNPs. The genotype frequencies of rs5472 or rs 9927981 were $\mathrm{A} / \mathrm{A}$ or $\mathrm{C} / \mathrm{C}(42.5 \%, \mathrm{n}=51)$, $\mathrm{A} / \mathrm{G}$ or $\mathrm{C} / \mathrm{T}(40.8 \%, \mathrm{n}=49)$, and $\mathrm{G} / \mathrm{G}$ or $\mathrm{T} / \mathrm{T}(16.7 \%, \mathrm{n}=20)$, respectively; and those of $\mathrm{rs} 4788458$ were $\mathrm{T} / \mathrm{T}(34.2 \%, \mathrm{n}=41)$, $\mathrm{T} / \mathrm{C}(40.0 \%, \mathrm{n}=48)$, and $\mathrm{C} / \mathrm{C}(25.8 \%, \mathrm{n}=31)$. The association between polymorphism rs5472/rs9927981 and prognosis, or between rs4788458 and prognosis, was analyzed further. However, no correlation was found between these SNPs and overall survival, regardless of subgroup analysis of gender, histology or concurrent therapy. These results suggest that the polymorphisms rs5472/rs9927981 and rs4788458 are not useful prognostic tools for patients with NSCLC treated with personalized peptide vaccination.
\end{abstract}

Correspondence to: Professor Akira Yamada, Cancer Vaccine Development Division, Kurume University Research Center for Innovative Cancer Therapy, 67 Asahi-machi, Kurume, Fukuoka 830-0011, Japan

E-mail: akiymd@med.kurume-u.ac.jp

Abbreviations: CTL, cytotoxic T-lymphocyte; Hp, haptoglobin; MST, median survival times; NSCLC, non-small cell lung cancer; OS, overall survival; PPV, personalized peptide vaccine; SNPs, single nucleotide polymorphisms

Key words: haptoglobin, SNPs, lung cancer, peptide vaccine, prognosis

\section{Introduction}

Lung cancer is the most commonly diagnosed cancer in the world and a leading cause of cancer-associated mortality (1). Diagnoses of non-small cell lung cancer (NSCLC) make up $\sim 80 \%$ of all lung cancer cases (2). Surgery is the standard treatment modality for patients with early stage NSCLC, however, this may not be appropriate for the majority of patients with NSCLC ( $>65 \%)$ who have already progressed to the advanced stages (stages IIIb/IV) at the time of diagnosis (3).

Improved knowledge of tumor biology has facilitated the development of molecular targeted therapies, including those against epidermal cell growth factor receptor mutations and the abnormal fusion of anaplastic lymphoma kinase, which has improved prognoses for patients with advanced NSCLC (4,5). However, prognosis remains inadequate and new treatment modalities are required.

Cancer immunotherapies have attracted great interest as promising novel therapeutic modalities for NSCLC. The personalized peptide vaccine (PPV), which was developed by the authors of the current study, is one such approach. PPV is designed to boost the patient's anti-cancer immunity by administering vaccine peptides matched to the patient's human leukocyte antigen (HLA)-A types and selected based on the pre-existing immunity of the patient prior to vaccination (6). PPV vaccine peptides are cytotoxic T-lymphocyte (CTL) epitopes derived from a number of tumor-associated antigens. The current list of 31 vaccine peptides consists of 12 , 9, 14, and 4 epitopes for HLA-A2, -A3 super-type (A3, A11, A31, or A33), -A24 and -A26, respectively (several epitopes are recognized by $>1$ type of HLA allele) $(6,7)$. Patients were subcutaneously injected weekly or bi-weekly with ISA51VG along with $\leq 4$ peptides selected from the 31 peptide candidates. Clinical studies of small cell and non-small cell lung cancers have indicated that PPV does not cause severe side effects but demonstrates potential immunological efficacy to some extent $(8,9)$. However, only a proportion of patients experience clinical benefits from such vaccines. Therefore, it is crucial to identify appropriate biomarkers to predict overall 
Table I. Characteristics of 120 patients with advanced non-small cell lung cancer treated with personalized peptide vaccines.

\begin{tabular}{|c|c|c|c|c|c|c|c|}
\hline \multirow[b]{2}{*}{ Characteristic } & \multirow[b]{2}{*}{ Total } & \multicolumn{3}{|c|}{ rs5472 (rs9927981) } & \multicolumn{3}{|c|}{ rs 4788458} \\
\hline & & $\begin{array}{c}\mathrm{A} / \mathrm{A}(\mathrm{C} / \mathrm{C}) \\
\mathrm{n}=51\end{array}$ & $\begin{array}{c}\mathrm{A} / \mathrm{G}(\mathrm{C} / \mathrm{T}) \\
\mathrm{n}=49\end{array}$ & $\begin{array}{c}\mathrm{G} / \mathrm{G}(\mathrm{T} / \mathrm{T}) \\
\mathrm{n}=20\end{array}$ & $\begin{array}{c}\mathrm{T} / \mathrm{T} \\
\mathrm{n}=41\end{array}$ & $\begin{array}{c}\mathrm{T} / \mathrm{C} \\
\mathrm{n}=48\end{array}$ & $\begin{array}{c}\mathrm{C} / \mathrm{C} \\
\mathrm{n}=31\end{array}$ \\
\hline OS, days & 120 & & & & & & \\
\hline $\begin{array}{l}\text { Median } \\
(95 \% \mathrm{CI})\end{array}$ & $\begin{array}{c}674 \\
(452-870)\end{array}$ & $\begin{array}{c}667 \\
(357-870)\end{array}$ & $\begin{array}{c}646 \\
(361-997)\end{array}$ & $\begin{array}{c}1182 \\
(231-N R)\end{array}$ & $\begin{array}{c}692 \\
(411-1200)\end{array}$ & $\begin{array}{c}639 \\
(302-996)\end{array}$ & $\begin{array}{c}753 \\
(234-\mathrm{NR})\end{array}$ \\
\hline Age, years & 120 & & & & & & \\
\hline $\begin{array}{l}\text { Median } \\
\text { (Range) }\end{array}$ & $\begin{array}{c}63 \\
(29-84)\end{array}$ & $\begin{array}{c}63 \\
(29-84)\end{array}$ & $\begin{array}{c}66 \\
(42-84)\end{array}$ & $\begin{array}{c}61.5 \\
(37-82)\end{array}$ & $\begin{array}{c}63 \\
(29-84)\end{array}$ & $\begin{array}{c}66.5 \\
(42-84)\end{array}$ & $\begin{array}{c}62 \\
(37-82)\end{array}$ \\
\hline \multicolumn{8}{|l|}{ Gender } \\
\hline Female/male & $59 / 61$ & $27 / 24$ & $24 / 25$ & $8 / 12$ & $21 / 20$ & $23 / 25$ & $15 / 16$ \\
\hline \multicolumn{8}{|l|}{ Stage } \\
\hline IIIb & 12 & 5 & 4 & 3 & 4 & 5 & 3 \\
\hline IV & 66 & 27 & 28 & 11 & 22 & 24 & 20 \\
\hline Recurrence & 42 & 19 & 17 & 6 & 15 & 19 & 8 \\
\hline \multicolumn{8}{|l|}{ Histology } \\
\hline Adeno & 100 & 44 & 41 & 15 & 38 & 39 & 23 \\
\hline SCC & 15 & 6 & 6 & 3 & 3 & 6 & 6 \\
\hline AdSq & 2 & 1 & 1 & 0 & 0 & 2 & 0 \\
\hline $\mathrm{LCC}$ & 2 & 0 & 1 & 1 & 0 & 1 & 1 \\
\hline Pleomorph & 1 & 0 & 0 & 1 & 0 & 0 & 1 \\
\hline \multicolumn{8}{|c|}{ Pre-vaccination regimen } \\
\hline $0-2$ & 66 & 28 & 26 & 12 & 23 & 25 & 18 \\
\hline$\geq 3$ & 54 & 23 & 23 & 8 & 18 & 23 & 13 \\
\hline
\end{tabular}

OS, overall survival; CI, confidence interval; Adeno, adenocarcinoma; SCC, squamous cell carcinoma; AdSq, adenosquamous carcinoma; LCC, large cell carcinoma; Pleomorph, pleomorphic carcinoma; NR, not reached.

survival (OS). It has been suggested that PD-1+ T-cell subsets in the peripheral blood may be developed as a prognostic marker for NSCLC patients treated with PPV (10). However, its prediction of patient prognosis remains insufficient and novel effective biomarkers are required.

Haptoglobin (Hp) is a plasma protein able to bind with high affinity to the free hemoglobin released from destroyed erythrocytes $(10,11)$. It contributes to the salvaging and recycling of hemoglobin and to antioxidation against hemoglobin-stimulated lipid peroxidation $(11,12)$. High levels of plasma Hp have been observed in a number of malignancies (13-18). In patients with NSCLC, plasma Hp levels are higher than those of healthy donors and correlate with aspects of disease progression, including clinical stage $(19,20)$. The presence of single nucleotide polymorphisms (SNPs) in the 5 flanking region of the $\mathrm{Hp}$ gene has been reported and some SNPs may affect plasma Hp levels $(21,22)$. However, to the best of our knowledge, an association between SNPs and the prognosis of patients with malignant diseases has not yet been reported.

The present study aimed to analyze the allele/genome frequency of six SNPs of the 5' flanking region of Hp genes in patients with NSCLC and investigate any associations Hp SNPs and patient prognosis.

\section{Materials and methods}

Clinical samples. A total of 120 patients with advanced NSCLC were subjected to analyses in the current study, which was conducted with the approval of the Kurume University Ethics Committee (Kurume, Japan). Patients were enrolled in phase II studies of PPV between December 2008 and January 2014 (clinical trial registry ID: UMIN1839 and UMIN2984) at Cancer Vaccine Center at Kurume University Medical Center; Department of Surgery, Kurume University Hospital; and Department of Pulmonary Medicine, Sendai Kousei Hospital. The designs of the clinical trials have been described in a previous report (9). Peripheral blood samples were obtained prior to and following one vaccination cycle that consisted of 6 or 8 peptide vaccinations. Peripheral blood mononuclear cells (PBMCs) were isolated by Ficoll density gradient separation, frozen and stored in the liquid nitrogen until later use.

Single nucleotide polymorphism analysis. The Hp polymorphism was determined by sequencing polymerase chain reaction (PCR) products of genomic DNA. Genomic DNA was extracted from PBMCs of 120 patients enrolled with a NucleoSpin ${ }^{\circledR}$ Blood kit (Macherey-Nagel, Düren, Germany), following the manufacturer's instructions. The target template was amplified 
Table II. SNPs of the 5' flanking region of the haptoglobin gene.

\begin{tabular}{|c|c|c|c|c|c|c|}
\hline SNPs & $\begin{array}{l}\text { Position from } \\
\text { transcription start }\end{array}$ & Alleles & Allele frequency & Genotypes & $\begin{array}{c}n \\
(\text { Total=120) }\end{array}$ & Genotype frequency \\
\hline \multirow[t]{3}{*}{ rs5467 } & -242 & $\mathrm{C}$ & 0.9167 & $\mathrm{C} / \mathrm{C}$ & 102 & 0.85 \\
\hline & & $\mathrm{T}$ & 0.0833 & $\mathrm{C} / \mathrm{T}$ & 16 & 0.1333 \\
\hline & & & & $\mathrm{T} / \mathrm{T}$ & 2 & 0.0167 \\
\hline \multirow[t]{3}{*}{ rs5468 } & -191 & $\mathrm{~T}$ & 0.9708 & $\mathrm{~T} / \mathrm{T}$ & 115 & 0.9583 \\
\hline & & G & 0.0292 & $\mathrm{~T} / \mathrm{G}$ & 3 & 0.025 \\
\hline & & & & $\mathrm{G} / \mathrm{G}$ & 2 & 0.0167 \\
\hline \multirow[t]{3}{*}{ rs190482744 } & -102 & A & 0.9917 & $\mathrm{~A} / \mathrm{A}$ & 118 & 0.9833 \\
\hline & & G & 0.0083 & $\mathrm{~A} / \mathrm{G}$ & 2 & 0.0167 \\
\hline & & & & $\mathrm{G} / \mathrm{G}$ & 0 & 0 \\
\hline \multirow[t]{3}{*}{ rs5472 } & -55 & A & 0.6292 & $\mathrm{~A} / \mathrm{A}$ & 51 & 0.425 \\
\hline & & G & 0.3708 & $\mathrm{~A} / \mathrm{G}$ & 49 & 0.4083 \\
\hline & & & & $\mathrm{G} / \mathrm{G}$ & 20 & 0.1667 \\
\hline \multirow[t]{3}{*}{ rs9927981 } & +131 & $\mathrm{C}$ & 0.6292 & $\mathrm{C} / \mathrm{C}$ & 51 & 0.425 \\
\hline & & $\mathrm{T}$ & 0.3708 & $\mathrm{C} / \mathrm{T}$ & 49 & 0.4083 \\
\hline & & & & $\mathrm{T} / \mathrm{T}$ & 20 & 0.1667 \\
\hline \multirow[t]{3}{*}{ rs4788458 } & +154 & $\mathrm{~T}$ & 0.5417 & $\mathrm{~T} / \mathrm{T}$ & 41 & 0.3417 \\
\hline & & $\mathrm{C}$ & 0.4583 & $\mathrm{~T} / \mathrm{C}$ & 48 & 0.4 \\
\hline & & & & $\mathrm{C} / \mathrm{C}$ & 31 & 0.2583 \\
\hline
\end{tabular}

SNPs, small nuclear polymorphisms.

using KOD-Plus (TOYOBO, Osaka, Japan) with the following thermocycling conditions: Initial denaturation at $94^{\circ} \mathrm{C}$ for 2 mins, followed by 35 cycles of $15 \mathrm{sec}$ denaturation at $94^{\circ} \mathrm{C}$, the $30 \mathrm{sec}$ annealing at $56^{\circ} \mathrm{C}$, and the one min elongation at $68^{\circ} \mathrm{C}$, and the $7 \mathrm{~min}$ final extension at $68^{\circ} \mathrm{C}$. A set of primers, forward 5'-TCAGTGTCACCATGATTATCCA-3' and reverse, 5'-GAT TTAACACACTAAGCCCTTTGG-3', amplified a 991 bp DNA fragment, consisting of the 5'-flanking region [840 bp upstream from the transcriptional start site $(+1)$ ], the starting codon, and the first intron $\leq 151$ bp downstream from the transcriptional start site of the Hp gene. The PCR products were purified by the NucleoSpin Gel PCR Clean-up kit (Macherey-Nagel) and subjected to sequence analyses performed by Eurofins Genomics (Tokyo, Japan). In addition to the PCR primers named above, a third forward primer, 5'-GCAATAGGGAGATGGCCACA-3' was used for the sequence analyses. The section of the current study regarding human genome analysis was approved by the Ethics Committee of Kurume University.

Statistical analysis. Possible associations between patient prognoses and the SNPs were examined using survival curves constructed by the Kaplan-Meier method and evaluated by the log-rank test. JMP software ver. 11 (SAS Institute, NC) was used for all analyses. $\mathrm{P}<0.05$ was considered to indicate a statistically significant difference.

\section{Results}

Patient characteristics. The characteristics of the 120 patients with advanced (stages IIIb and V) or recurrent NSCLC receiving PPV treatment are presented in Table I. There were 59 females and 61 males, with a median age of 63 years (range, 29-84 years) at the time of enrollment. The clinical stages of the patients were determined according to the TNM classification of malignant tumors (7th ed.) provided by Union for International Cancer Control, and were as follows: 12 cases in stage IIIb, 66 in stage IV, and 42 with recurrence. Tumor histology consisted of adenocarcinoma $(n=100)$, squamous cell carcinoma $(n=15)$, adenosquamous carcinoma $(n=2)$, large cell carcinoma $(n=2)$ and pleomorphic carcinoma $(n=1)$. By the time PPV treatment began, 111 of the 120 patients had failed $\geq 1$ chemotherapy regimen: $25,32,19$, and 35 patients had failed 1, 2, 3, or 4-12 regimens, respectively. A total of 9 patients were naïve to any chemotherapy regimens prior to treatment with PPV.

Polymorphism of 5'flanking region of haptoglobingene. A total of six SNPs were identified from the genomic DNA samples of NSCLC patients: rs5467 (-242C>T), rs5468 (-191T>G), rs190482744 (-102A>G), rs5472 $(-55 \mathrm{~A}>\mathrm{G})$, rs9927981 $(+131 \mathrm{C}>\mathrm{T})$ and $\mathrm{rs} 4788458(+154 \mathrm{~T}>\mathrm{C})$. Minor alleles of rs5467, rs5468, and rs190482744 were rarely detected. By contrast, those of rs5472, rs9927981, and rs4788458 were abundant. The detected number and frequency of each allele and genotype of the SNPs are presented in Table II. Allele frequencies of rs5472A $>\mathrm{G}$ and $\mathrm{rs} 9927981 \mathrm{C}>\mathrm{T}$ were the same and all patients with rs5472A possessed the rs9927981C allele. These results suggest that the rs5472 and rs992798 are completely linked to each other. By contrast, no such linkage was observed between rs4788458 and rs5472/rs9927981. 
A Total cases

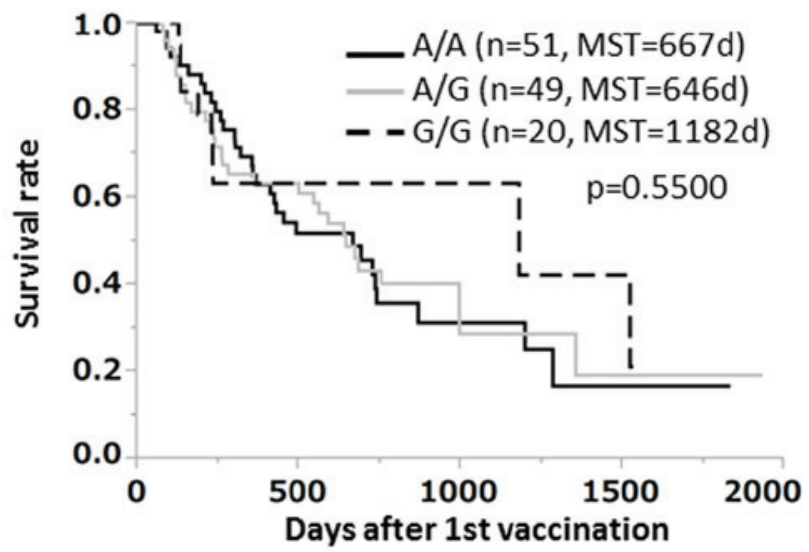

C Female

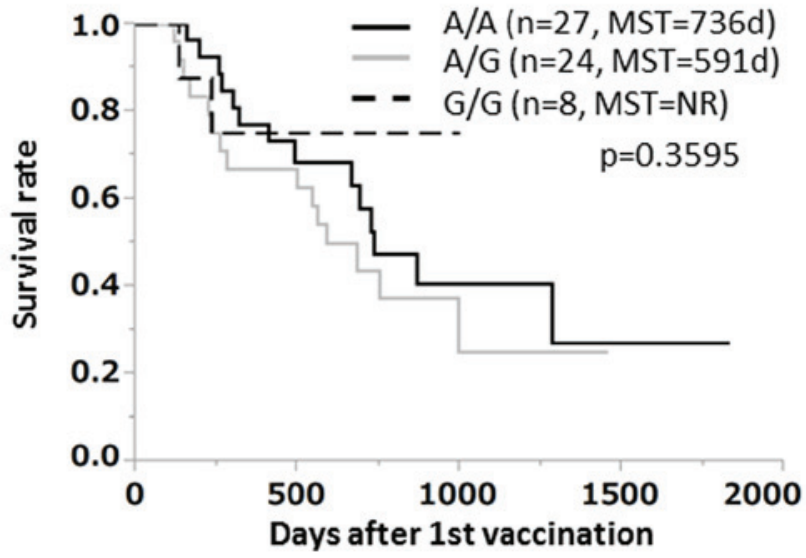

E Concurrent therapy

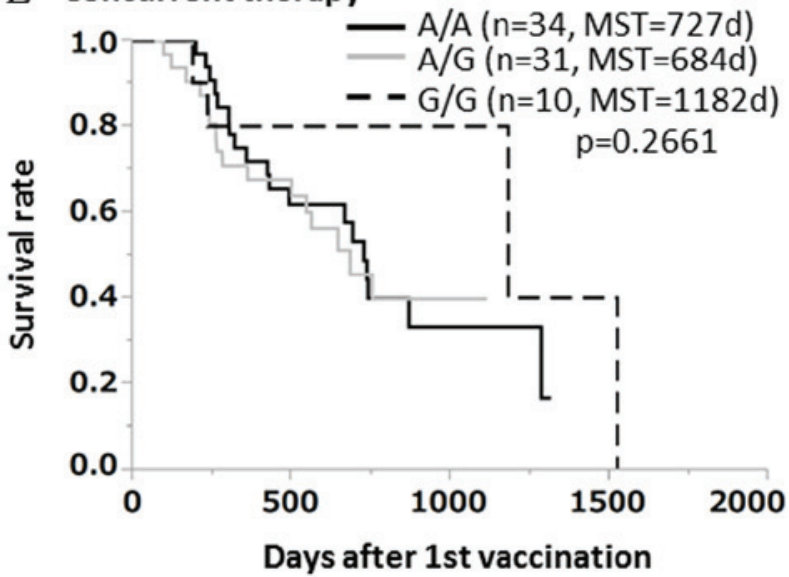

B Male

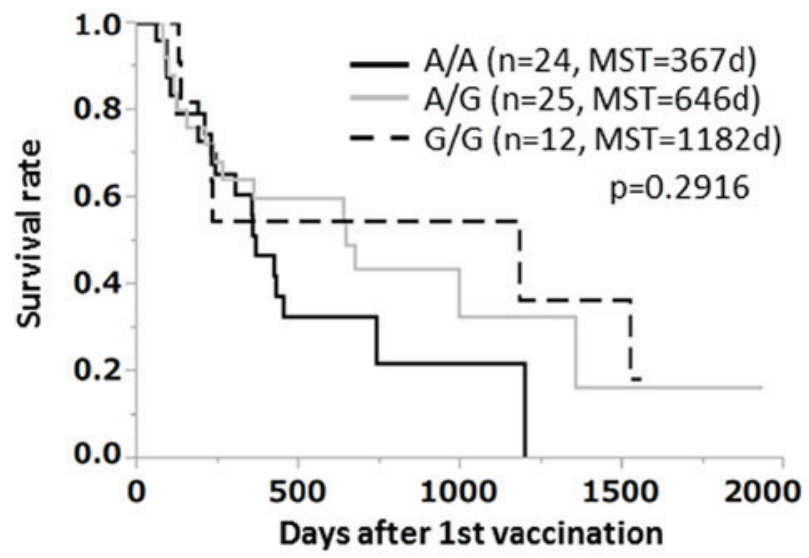

D Adenocarcinoma

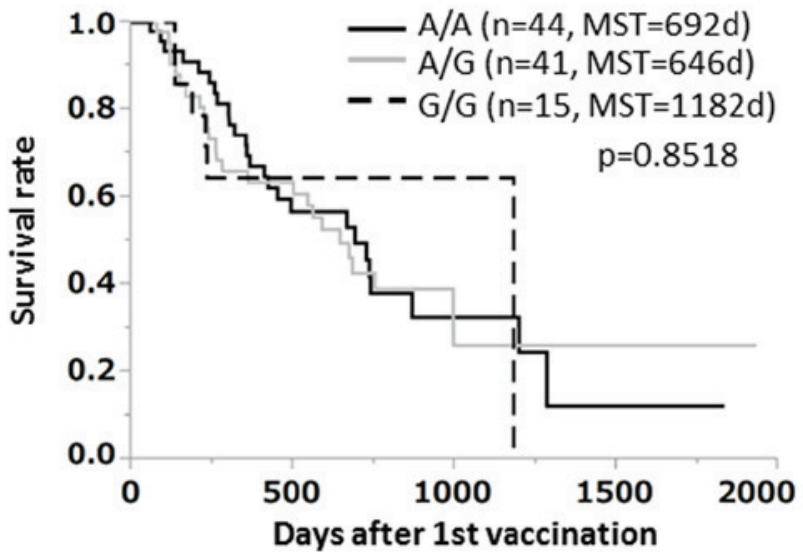

F Monotherapy

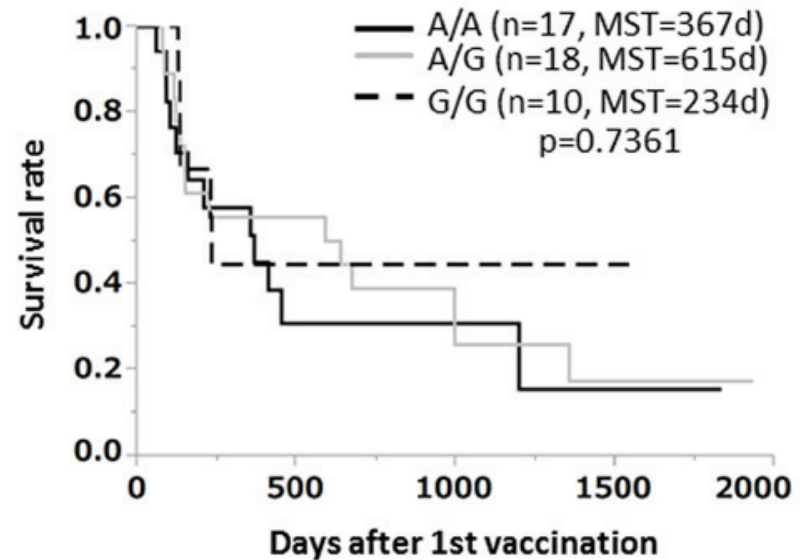

Figure 1. Hp SNP rs5472/rs9927981 and prognosis in NSCLC. Genotypes A/A, A/G, and G/G of rs5472 are compatible with C/C, C/T, and T/T of rs9927981 and only the genotypes of rs5472 are presented in the figures. (A) The association between SNP rs5472/rs9927981 and OS rates of the cases was analyzed by constructing a Kaplan-Meier plot using the log-rank test. Associations between SNP 5472/rs9927981 and OS were analyzed among (B) male (n=61) and (C) female ( $n=59)$ patients, (D) patients with adenocarcinoma $(n=100)$ and patients undergoing $(E)$ combination therapy $(n=75)$ or $(F)$ monotherapy $(n=45)$. Hp, haptoglobin; SNP, small nuclear polymorphisms; NSCLC, non-small cell lung cancer; OS, overall survival.

The minor allele frequencies of rs5472/rs9927981 and rs4788458 were higher than those of the other three SNPs. The genotype frequencies of rs5472 or rs9927981 were A/A or $\mathrm{C} / \mathrm{C}(42.5 \%, \mathrm{n}=51), \mathrm{A} / \mathrm{G}$ or $\mathrm{C} / \mathrm{T}(40.8 \%, \mathrm{n}=49)$, and $\mathrm{G} / \mathrm{G}$ or $\mathrm{T} / \mathrm{T}(16.7 \%, \mathrm{n}=20)$, respectively, and those of rs 4788458 were $\mathrm{T} / \mathrm{T}(34.2 \%, \mathrm{n}=41), \mathrm{T} / \mathrm{C}(40.0 \%, \mathrm{n}=48)$, and $\mathrm{C} / \mathrm{C}(25.8 \%, \mathrm{n}=31)$, respectively. The genotype frequencies of rs 5472 observed in the current study are similar to those documented in a previous report on a Japanese population (140/385: 36.4\%, 197/385: $51.2 \%$, and 48/385: $12.4 \%$, respectively) (22), with no significant differences.

Hp SNP rs5472/rs9927981 and prognosis in NSCLC. Associations between the Hp SNPs rs5472/rs9927981 and the OS of NSCLC patients were assessed by a Kaplan-Meier plot (Fig. 1). Genotypes A/A, A/G, and G/G of rs5472 are compatible with 
A Total cases

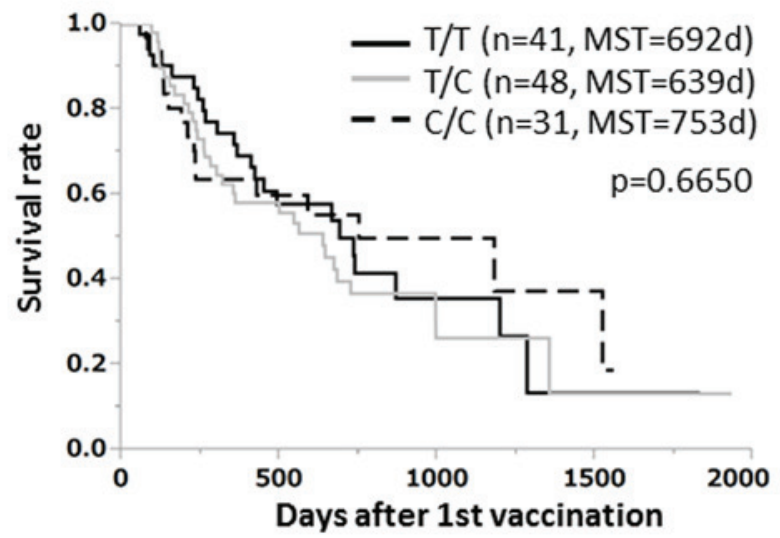

C Female

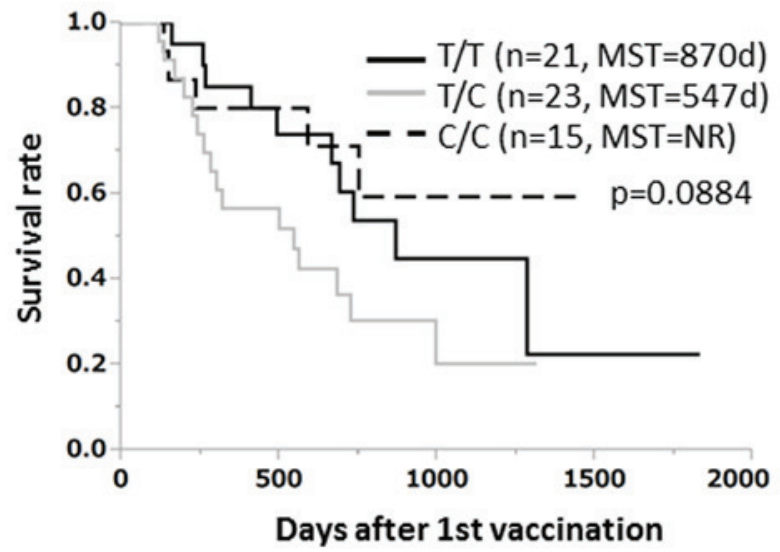

\section{E Concurrent therapy}

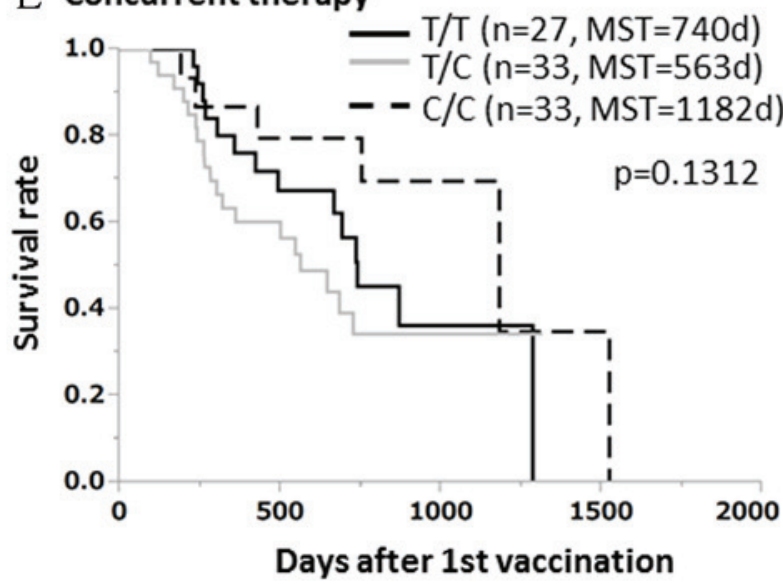

B Male

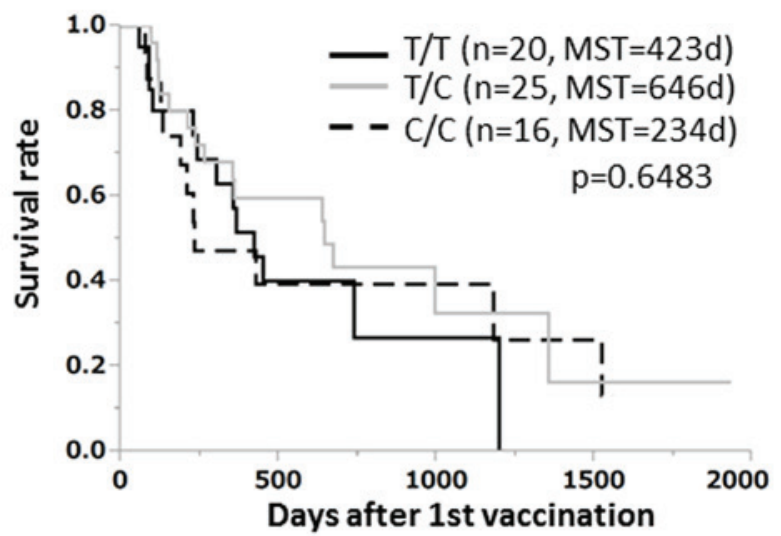

D Adenocarcinoma

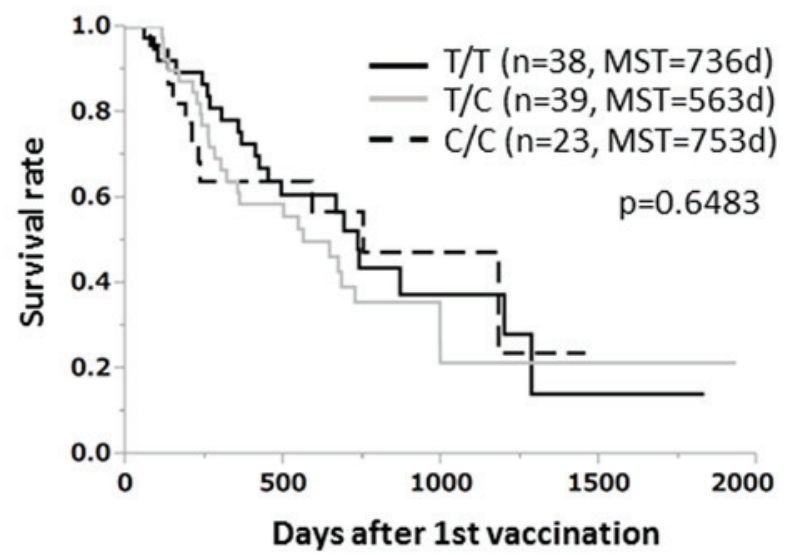

F Monotherapy

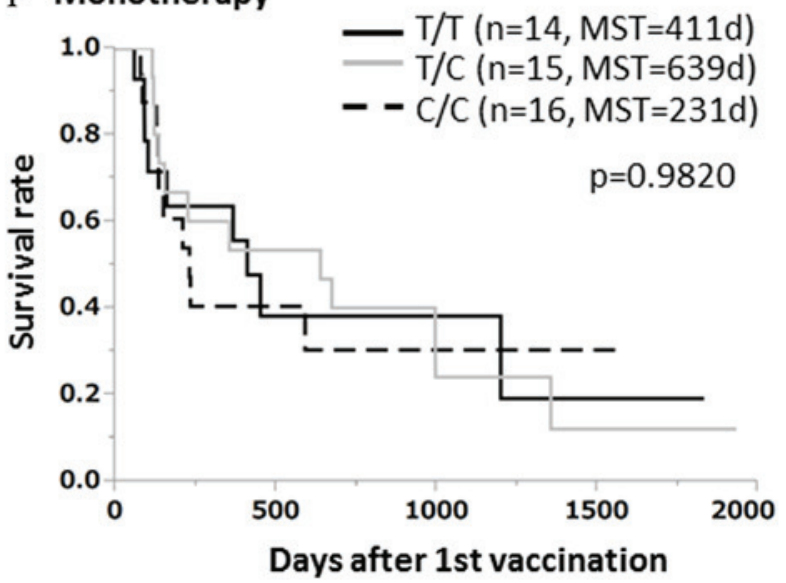

Figure 2. Hp SNP rs4788458 and prognosis in NSCLC. (A) The associations between SNP rs4788458 and OS of the total cases was analyzed by the Kaplan-Meier plot with the log-rank test. Associations between SNP rs4788458 and OS were analyzed among (B) male (n=61) and (C) female (n=59) patients, among patients with (D) adenocarcinoma $(n=100)$ and patients undergoing $(E)$ combination therapy $(n=75)$ or $(F)$ monotherapy $(n=45)$. Hp, haptoglobin; SNP, small nuclear polymorphisms; NSCLC, non-small cell lung cancer; OS, overall survival.

$\mathrm{C} / \mathrm{C}, \mathrm{C} / \mathrm{T}$, and $\mathrm{T} / \mathrm{T}$ of rs9927981 therefore, only results from SNP rs5472 genotype are presented in Fig. 1. The median survival times (MST) from the date of the first vaccination in the A/A, A/G, and $\mathrm{G} / \mathrm{G}$ groups of rs5472 were 667, 646, and 1182 days, respectively (Fig. 1A). No significant differences in MST were observed among the genotype groups.

Subgroup analyses by gender and tumor histology type were subsequently performed. The histology type of the majority of patients was adenocarcinoma, thus only the adenocarcinoma group $(n=100)$ was subjected to subgroup analysis by tumor histology type. Kaplan-Meier plots for male, female, and all adenocarcinoma patients were constructed (Fig. 1B-D). Statistical analyses of the subgroups revealed no correlations between SNP rs5472/rs9927981 and OS among male, female, or adenocarcinoma patients. In addition, possible associations between the rs5472/rs9927981 genotypes and OS in the 
patients with bone metastasis were examined. No significant correlations, however, were observed (data not shown).

Previous studies have suggested that patients concurrently treated with PPV and chemotherapy (concurrent therapy) exhibit better prognosis compared to those treated with PPV alone (monotherapy), in castration-resistant prostate cancer, pancreatic cancer, colorectal cancer, and NSCLC (23-26). Similar results were observed in the present study; patients treated with concurrent therapy had a significantly longer MST ( $n=75,736$ days) than patients treated with PPV monotherapy ( $n=45,367$ days; $P=0.038$; data not shown). However, the OS did not differ among patients with SNP rs5472/rs9927981 treated with either concurrent therapy or PPV monotherapy (Fig. 1E and F, respectively).

Hp SNP rs4788458 and prognosis in NSCLC. The possible association between Hp SNP rs4788458 and OS was assessed (Fig. 2A). The MST of OS in the T/T, T/C, and C/C groups of rs4788458 were 692, 639, and 753 days, respectively. Similar to the case with rs5472/rs9927981, there were no significant differences among the genotype groups of rs4788458. In addition, subgroup analyses of gender, histology, or concurrent therapy were performed (Fig. 2B-F). Again, however, there were no significant differences among the genotype groups of rs 4788458 .

\section{Discussion}

A number of studies have investigated possible associations between the SNPs of various genes and disease susceptibility or prognosis. Correlations have previously been observed between the SNPs of the TNF- $\alpha$ gene, and susceptibility to human T-cell lymphotropic virus 1 uveitis (27) and rheumatoid arthritis (28). Furthermore, possible associations between SNPs and the prognosis of cancer patients have been previously investigated. In NSCLC, such correlations were demonstrated between prognosis and the SNPs of DNA excision repair 1/2 endonuclease non-catalytic subunit (29), xeroderma pigmentosum group D (30) and vesicular epidermal cell growth factor (31).

Patients with NSCLC exhibit higher plasma Hp protein levels than healthy donors and those levels correlate with aspects of disease progression, including clinical stage $(19,20)$. Additionally, correlations between plasma Hp levels and patient prognosis have been reported in other types of cancer (32). The 5' flanking regions of genes generally control gene transcription through the binding of transcription factors. Therefore, in the current study, the SNPs of the 5' flanking region of the Hp gene were investigated, and six SNPs of the Hp gene in NSCLC were identified. Subsequently, possible correlations between the SNPs and OS in patients with NSCLC treated with PPV were investigated, but none were observed. Another research group have obtained different results in patients with castration-resistant prostate cancer treated with PPV; they observed a certain degree of correlation between Hp SNP rs5472 and OS (Miyazaki et al, manuscript submitted for publication). Therefore, in the current study, further subgroup analyses of gender, histology or concurrent therapy were performed, however, no correlations were observed. At present, it is unclear why such different results were obtained in patients with NSCLC and castration-resistant prostate cancer. It is noted that Motifmap analysis, an in silico analysis of transcription factor binding sites $(33,34)$, of the Hp gene suggested that there were seven binding sites (-691, -432, $-159,-148,-84,+9$, and +328 ) for transcription factors in the 5 ' flanking region of the $\mathrm{Hp}$ gene. These sites do not include the six SNPs $(-242,-191,-102,-55,+131$, and +154) identified in the present study.

The present study investigated possible correlations between the SNPs of the Hp gene and immune responses to the vaccinated peptides: responses to immunoglobulin $\mathrm{G}$ and CTL. Again, however, no correlation was observed (data not shown).

In conclusion, the current study investigated possible correlations between $\mathrm{Hp}$ polymorphisms and the prognosis of advanced NSCLC patients treated with PPV. However, no correlations between the Hp SNPs and prognosis in advanced NSCLC were identified. This suggests that the SNPs of the Hp gene are not suitable biomarkers for NSCLC.

\section{Acknowledgements}

The present study was supported in part by grants from the Private University Strategic Research Foundation Support Program of the Ministry of Education, Culture, Sports, Science and Technology of Japan (MEXT), the Regional Innovation Cluster Program of MEXT, and the Sendai Kousei Hospital (Sendai, Miyagi, Japan).

\section{References}

1. International Agency for Research on Cancer, World Health Organization. GLOBOCAN 2012: Estimated cancer incidence, mortality and prevalence worldwide in 2012. http://globocan. iarc.fr/Pages/fact_sheets_cancer.aspx. Accessed July 31, 2015.

2. Devesa SS, Bray F, Vizcaino AP and Parkin DM: International lung cancer trends by histologic type: Male: Female differences diminishing and adenocarcinoma rates rising. Int J Cancer 117: 294-299, 2005

3. Reck M,Heigener DF, Mok T, Soria JC and Rabe KF: Management of non-small-cell lung cancer: Recent developments. Lancet 382: 709-719, 2013.

4. Forde PM and Ettinger DS: Targeted therapy for non-small-cell lung cancer: Past, present and future. Expert Rev Anticancer Ther 13: 745-758, 2013.

5. Gridelli C, Peters S, Sgambato A, Casaluce F, Adjei AA and Ciardiello F: ALK inhibitors in the treatment of advanced NSCLC. Cancer Treat Rev 40: 300-306, 2014.

6. Yamada A, Sasada T, Noguchi M and Itoh K: Next-generation peptide vaccines for advanced cancer. Cancer Sci 104: 15-21, 2013.

7. Sasada T, Yamada A, Noguchi M and Itoh K: Personalized peptide vaccine for treatment of advanced cancer. Curr Med Chem 21: 2332-2345, 2014.

8. Terazaki Y, Yoshiyama K, Matsueda S, Watanabe $\mathrm{N}$, Kawahara A, Naito Y, Suekane S, Komatsu N, Ioji T, Yamada A, et al: Immunological evaluation of personalized peptide vaccination in refractory small cell lung cancer. Cancer Sci 103: 638-644, 2012

9. Yoshiyama K, Terazaki Y, Matsueda S, Shichijo S, Noguchi M, Yamada A, Mine T, Ioji T, Itoh K, Shirouzu K, et al: Personalized peptide vaccination in patients with refractory non-small cell lung cancer. Int J Oncol 40: 1492-1500, 2012.

10. Waki K, Yamada T, Yoshiyama K, Terazaki Y, Sakamoto S, Matsueda S, Komatsu N, Sugawara S, Takamori S, Itoh K and Yamada A: PD-1 expression on peripheral blood T-cell subsets correlates with prognosis in non-small cell lung cancer. Cancer Sci 105: 1229-1235, 2014.

11. Gutteridge JM: The antioxidant activity of haptoglobin towards haemoglobin-stimulated lipid peroxidation. Biochim Biophys Acta 917: 219-223, 1987. 
12. Gutteridge JM and Smith A: Antioxidant protection by haemopexin of haem-stimulated lipid peroxidation. Biochem J 256: 861-865, 1988.

13. Thompson S and Turner GA: Elevated levels of abnormally-fucosylated haptoglobins in cancer sera. Br J Cancer 56 : 605-610, 1987.

14. Okuyama N, Ide Y, Nakano M, Nakagawa T, Yamanaka K, Moriwaki K, Murata K, Ohigashi H, Yokoyama S, Eguchi H, et al: Fucosylated haptoglobin is a novel marker for pancreatic cancer: A detailed analysis of the oligosaccharide structure and a possible mechanism for fucosylation. Int J Cancer 118: 2803-2808, 2006.

15. Fujimura T, Shinohara Y, Tissot B, Pang PC, Kurogochi M, Saito S, Arai Y, Sadilek M, Murayama K, Dell A, et al: Glycosylation status of haptoglobin in sera of patients with prostate cancer vs. Benign prostate disease or normal subjects. Int J Cancer 122: 39-49, 2008.

16. Ahmed N, Barker G, Oliva KT, Hoffmann P, Riley C, Reeve S Smith AI, Kemp BE, Quinn MA and Rice GE: Proteomic-based identification of haptoglobin-1 precursor as a novel circulating biomarker of ovarian cancer. Br J Cancer 91: 129-140, 2004.

17. Zhao C, Annamalai L, Guo C, Kothandaraman N, Koh SC, Zhang $\mathrm{H}$, Biswas A and Choolani M: Circulating haptoglobin is an independent prognostic factor in the sera of patients with epithelial ovarian cancer. Neoplasia 9: 1-7, 2007.

18. Dowling P, Clarke C, Hennessy K, Torralbo-Lopez B, Ballot J, Crown J, Kiernan I, O'Byrne KJ, Kennedy MJ, Lynch V and Clynes M: Analysis of acute-phase proteins, AHSG, C3, CLI, HP and SAA, reveals distinctive expression patterns associated with breast, colorectal and lung cancer. Int J Cancer 131: 911-923, 2012.

19. Hoagland LF IV, Campa MJ, Gottlin EB, Herndon JE II and Patz EF Jr: Haptoglobin and posttranslational glycan-modified derivatives as serum biomarkers for the diagnosis of nonsmall cell lung cancer. Cancer 110: 2260-2268, 2007.

20. Hansen JE, Iversen J, Lihme A and Bøg-Hansen TC: Acute phase reaction, heterogeneity, and microheterogeneity of serum proteins as nonspecific tumor markers in lung cancer. Cancer 60: 1630-1635, 1987.

21. Teye K, Soejima M, Quaye IK, Pang H, Tsuneoka M, Koda Y and Kimura H: Haptoglobin gene promoter polymorphism and haplotypes are unique in different populations. Hum Biol 78: 121-126, 2006.

22. Soejima M, Sagata N, Komatsu N, Sasada T, Kawaguchi A, Itoh K and Koda Y: Genetic factors associated with serum haptoglobin level in a Japanese population. Clin Chim Acta 433: 54-57, 2014

23. Noguchi M, Itoh K, Suekane S, Morinaga A, Sukehiro A, Suetsugu N, Katagiri K, Yamada A and Noda S: Immunological monitoring during combination of patient-oriented peptide vaccination and estramustine phosphate in patients with metastatic hormone refractory prostate cancer. Prostate 60: 32-45, 2004
24. Yanagimoto H, Mine T, Yamamoto K, Satoi S, Terakawa N, Takahashi K, Nakahara K, Honma S, Tanaka M, Mizoguchi J, et al: Immunological evaluation of personalized peptide vaccination with gemcitabine for pancreatic cancer. Cancer Sci 98: 605-611, 2007.

25. Yanagimoto $H$, Shiomi $H$, Satoi S, Mine T, Toyokawa $H$, Yamamoto T, Tani T, Yamada A, Kwon AH, Komatsu N, et al: A phase II study of personalized peptide vaccination combined with gemcitabine for non-resectable pancreatic cancer patients. Oncol Rep 24: 795-801, 2010.

26. Yamada T, Terazaki Y, Sakamoto S, Yoshiyama K, Matsueda S, Komatsu N, Waki K, Yamada A, Kawahara A, Kage M, et al: Feasibility study of personalized peptide vaccination for advanced non-small cell lung cancer patients who failed two or more treatment regimens. Int J Onco 46: 55-62, 2015.

27. Seki N, Yamaguchi K, Yamada A, Kamizono S, Sugita S, Taguchi C, Matsuoka M, Matsumoto H, Nishizaka S, Itoh K and Mochizuki M: Polymorphism of the 5'-flanking region of the tumor necrosis factor (TNF)-alpha gene and susceptibility to human T-cell lymphotoropic virus type I (HTLV-1) uveitis. J Infect Dis 180: 880-883, 1999.

28. Seki N, Kamizono S, Yamada A, Higuchi T, Matsumoto H, Niiya F, Kimura A, Tsuchiya K, Suzuki R, Date Y, et al: Polymorphisms in the 5'-flanking region of the tumor necrosis factor-alpha gene in patients with rheumatoid arthritis. Tissue Antigens 54: 194-197, 1999.

29. Yang Y and Xian L: The association between the ERCC1/2 polymorphisms and the clinical outcomes of the platinum-based chemotherapy in non-small cell lung cancer (NSCLC): A systematic review and meta-analysis. Tumour Biol 35: 2905-2921, 2014.

30. Qiu M, Yang X, Hu J, Ding X, Jiang F, Yin R and Xu L: Predictive value of XPD polymorphisms on platinum-based chemotherapy in non-small cell lung cancer: A systematic review and meta-analysis. PLoS One 8: e72251, 2013.

31. Jain L, Vargo CA, Danesi R, Sissung TM, Price DK, Venzon D, Venitz J and Figg WD: The role of vascular endothelial growth factor SNPs as predictive and prognostic markers for major solid tumors. Mol Cancer Ther 8: 2496-2508, 2009.

32. Wassell J: Haptoglobin: Function and polymorphism. Clin Lab 46: 547-552, 2000.

33. Xie X, Rigor P and Baldi P: MotifMap: A human genome-wide map of candidate regulatory motif sites. Bioinformatics 25: 167-174, 2009.

34. MotifMap: Genome-wide maps of regulatory elements. http://motifmap.ics.uci.edu/. Accessed July 31, 2015. 